Christina Drobe

Was ist der Sinn der Geschichte? 


\section{Tillich Research}

Tillich-Forschungen

Recherches sur Tillich

Edited by

Christian Danz, Marc Dumas, Verna Ehret, and Werner Schüßler

\section{Volume 21}


Christina Drobe

\section{Was ist der Sinn der Geschichte?}

Theologische Reflexionen

zur Eschatologie von Paul Tillich 
ISBN 978-3-11-072090-7

e-ISBN (PDF) 978-3-11-073318-1

e-ISBN (EPUB) 978-3-11-073329-7

ISSN 2192-1938

Library of Congress Control Number: 2021943972

Bibliografische Information der Deutschen Nationalbibliothek

Die Deutsche Nationalbibliothek verzeichnet diese Publikation in der Deutschen Nationalbibliografie; detaillierte bibliografische Daten sind im Internet über http://dnb.dnb.de abrufbar.

(C) 2021 Walter de Gruyter GmbH, Berlin/Boston

Druck und Bindung: $\mathrm{CPI}$ books $\mathrm{GmbH}$, Leck

www.degruyter.com 
Für Daniel Geese 
